\title{
ROYAL RESEARCH SHIP DISCOVERY II
}

\author{
I $929-62$
}

By H. F. P. Herdman

(National Institute of Oceanography, Wor:nley, Godalming, England)

There has been little that was spectacular about the career of the Royal Research Ship Discovery $I I$ and yet, when she paid-off finally for disposal, in September 1962, after 33 years of an active life, the sum of her activities was quite impressive. Built in excess of Lloyd's highest class for navigation in ice in 1929 , for the Discovery Committec of the Colonial Office, to continue their research into the habitat of the whale in Antarctic waters, Discovery II became the property of the National Oceanographic Council in I 949. Between I929 and I939 she steamed over half a million sea miles in completing five two-year commissions in the Southern Ocean and around the fringes of Antarctica. One circumpolar voyage was made during the winter of 1932 and the continent was again circumnavigated in $193^{8-}-39$, this time in the summer. In 1936 she was diverted from her normal work to pick up Lincoln Ellsworth after his successful flight across Antarctica. This entailed passage through some 400 miles $(645 \mathrm{~km}$.) of pack ice in the Ross Sea on the outward journey.

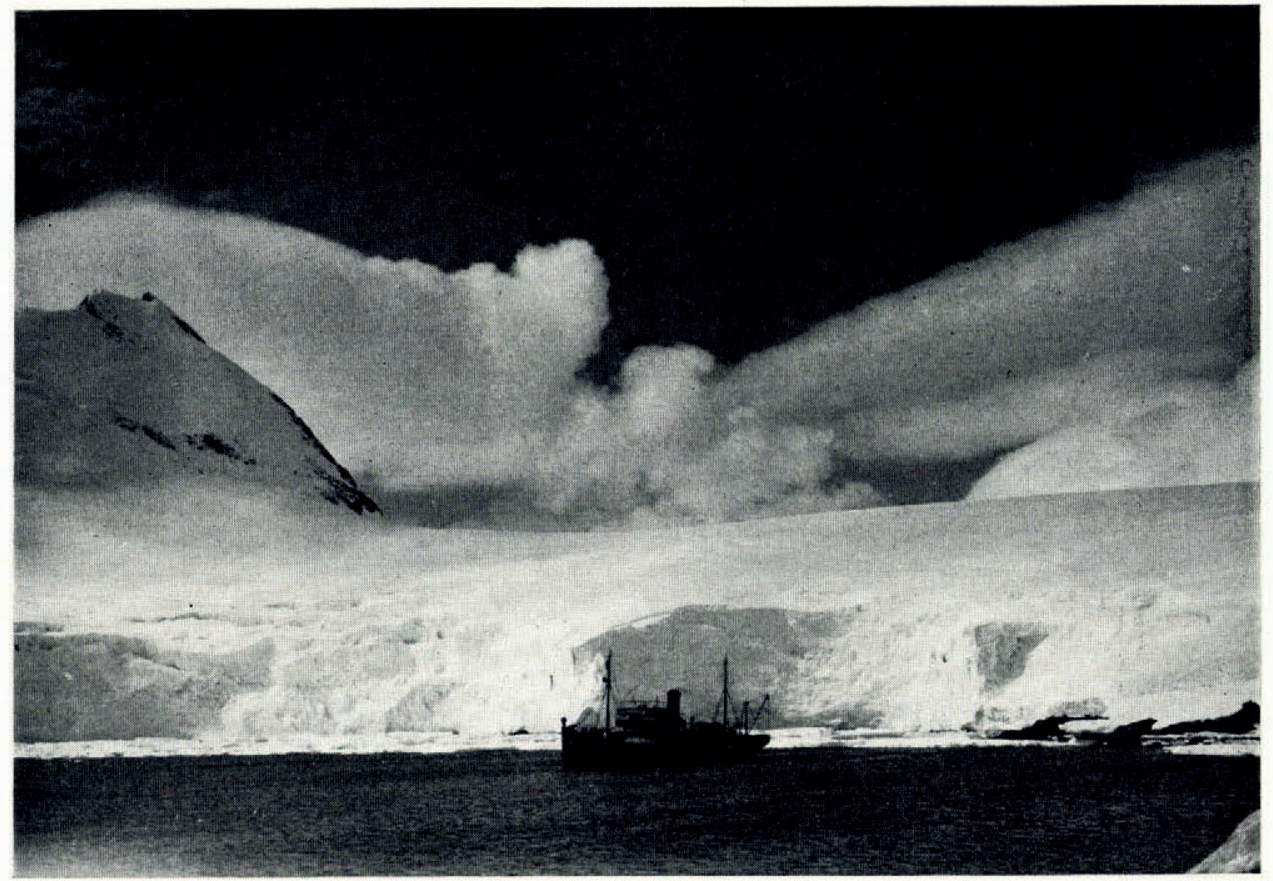

Fig. I. R.R.S. Discovery II at anchor in Port Lockroy, Graham Land. Photograph by National Institule of Oceanography

In 1940 Discovery $I I$ was requisitioned for war service and was first employed as an armed boarding vessel in the Denmark Strait. Later, she was used by Trinity House, and among her jobs was that of laying the buoys for a convoy anchorage in Iceland. A "near-miss" from a mine which, except for her original strength, might well have caused her loss, only put her 


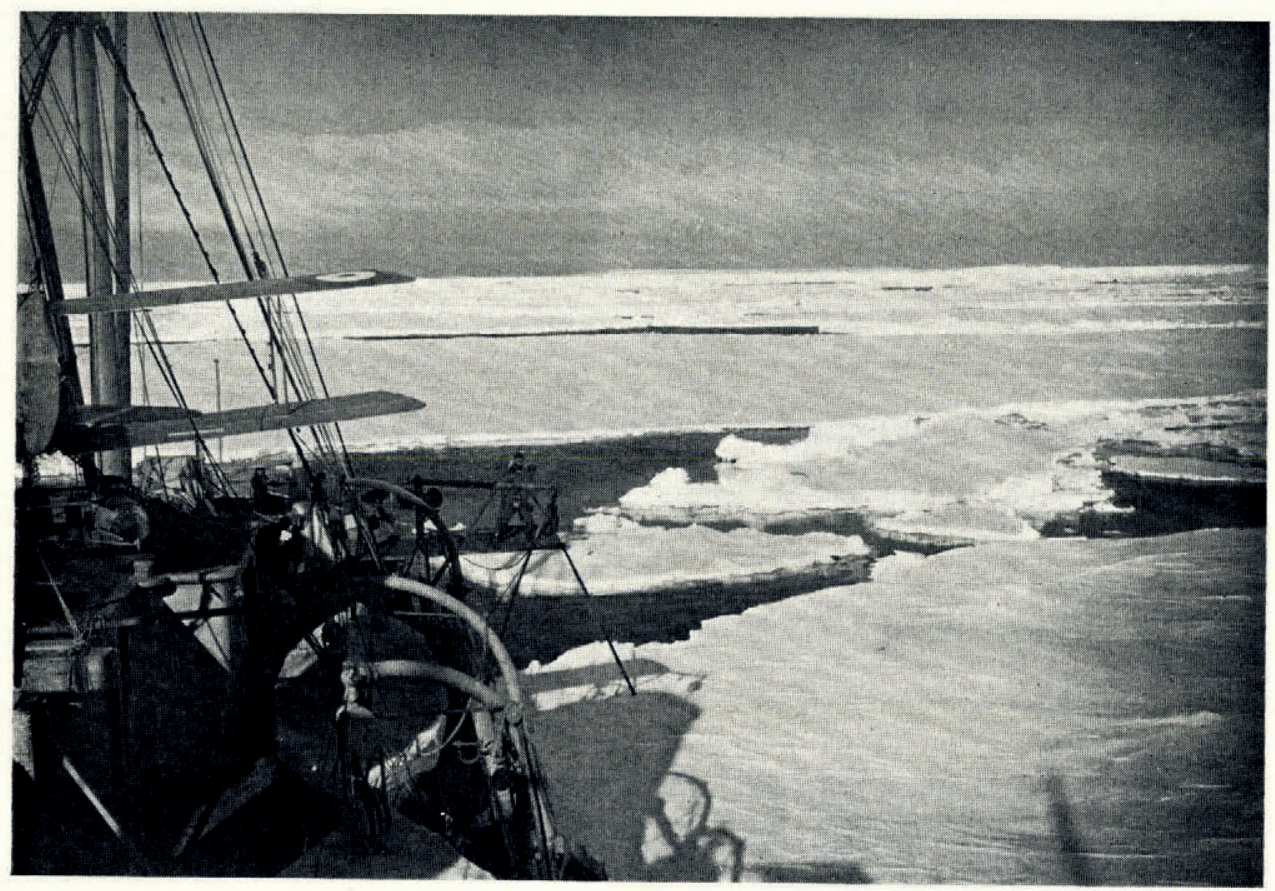

Fig. 2. Passage through the Ross Sea to rescue Lincoln Ellsworth. Io November 1936. Photograph by National Institute of Oceanography

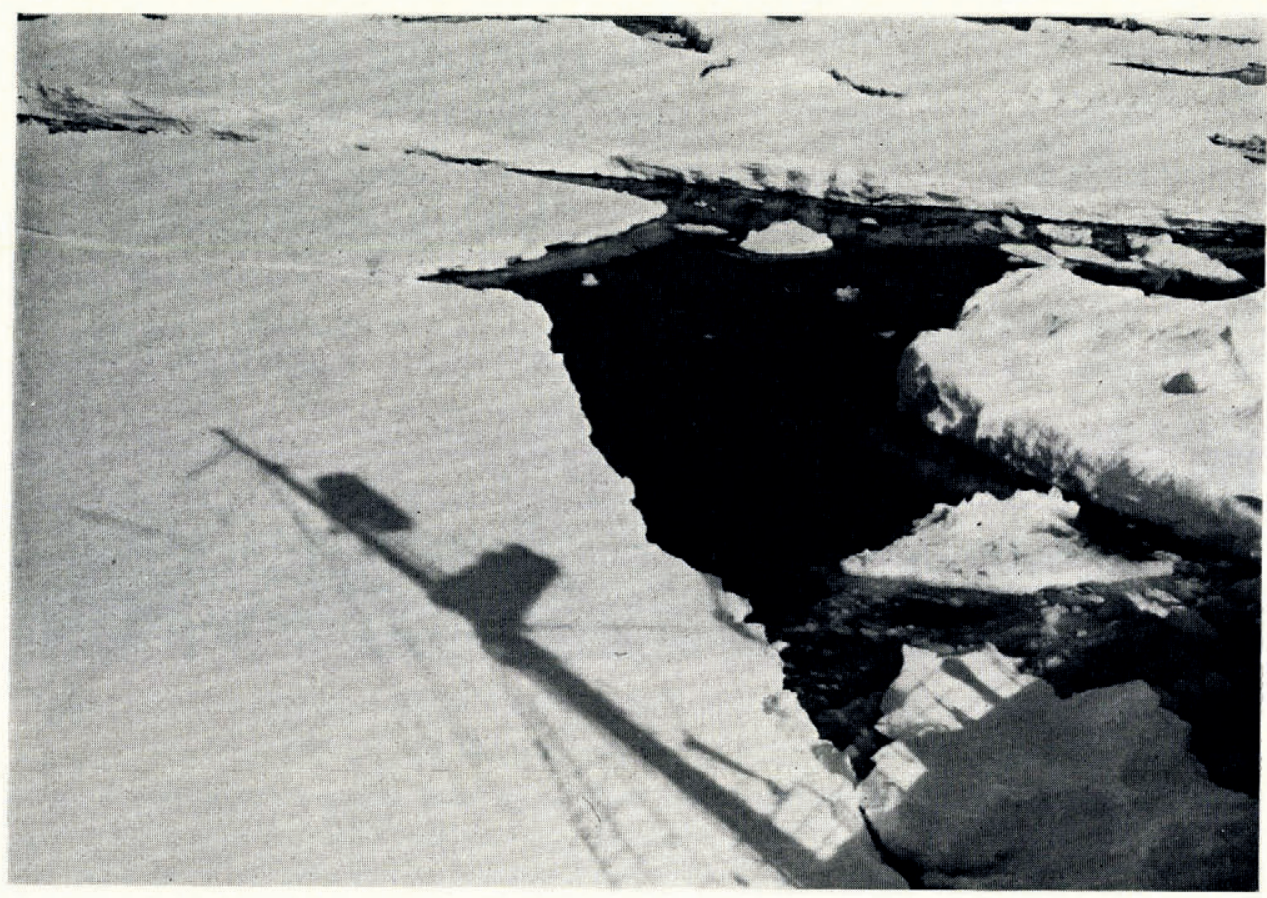

Fig. 3. Heavy pack ice. Note the shadow of R.R.S. Discovery II. Photograph by National Institute of Oceanography 
out of action for a short period and she was soon back in service. Discovery $I I$ was then transferred to the service of the Commissioners for Irish Lights, until 1948, when we were able to get her back for rehabilitation as a research ship.

Following her reconstruction she sailed in $195^{\circ}$ to continue the survey of the Southern Ocean begun in 1925. Again, Discovery II circumnavigated Antarctica in winter, under rather more trying conditions this time in that only the Master, the Senior Scientist and the Bos'un had had any previous experience at all of navigation in ice.

When Discovery II made her first cruise to Antarctic waters detailed information on pack ice was negligible. Few ships other than the early sealers, whalers and those ships which comprised the various Antarctic expeditions had visited these waters and, to them, the pack ice they had to push through was merely another hazard to be overcome on their passage to the continent. Hence, when Discovery II began her series of cruises in Antarctic waters, few observations had been made either on the movement or distribution of the pack ice and this

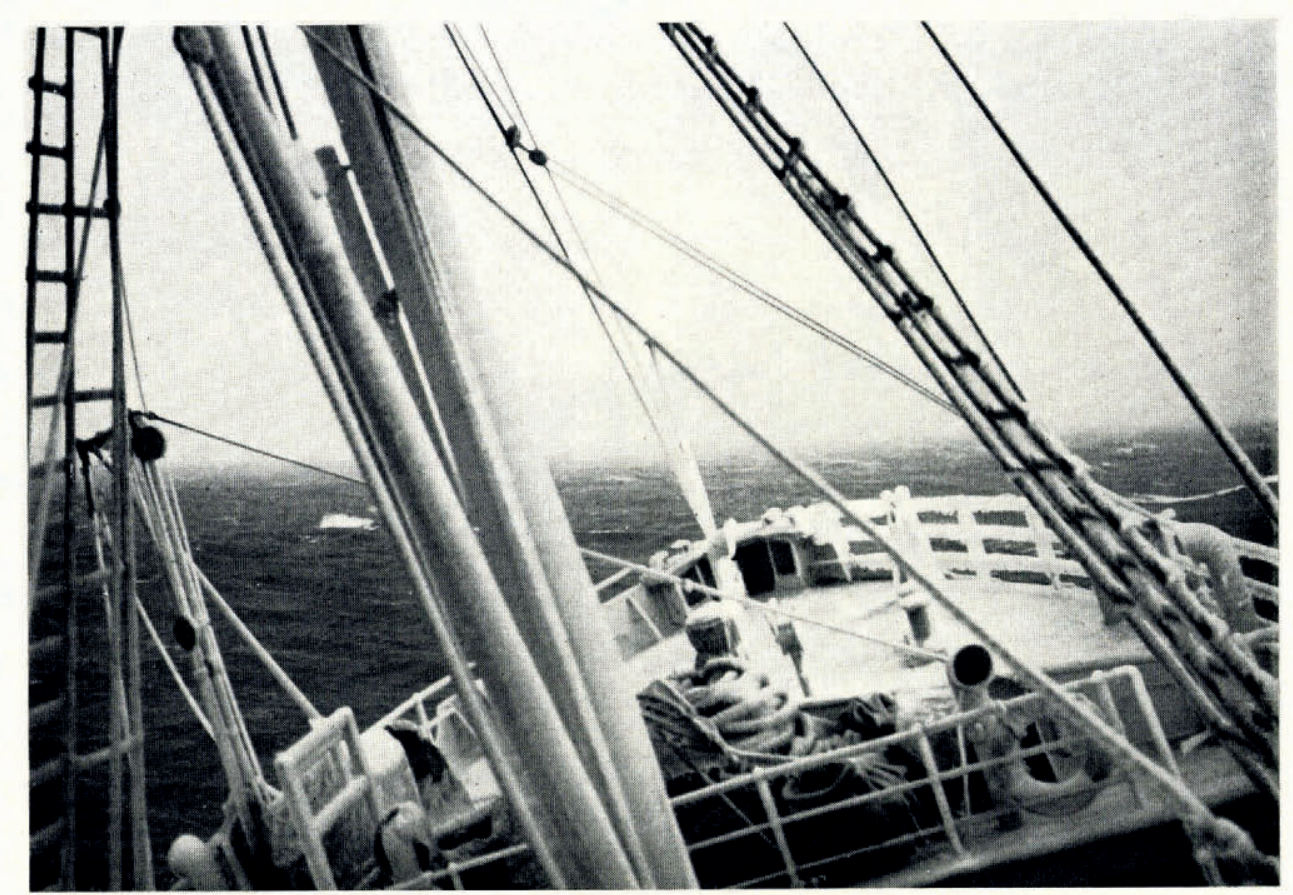

Fig. 4. Blizzard conditions near Bouvetoya. July 1938. Photograph by National Institule of Oceanography

lack of information-coupled with a distinctly hazy knowledge of the oceanic conditions prevailing in those waters - was an undoubted disadvantage. Like the early explorers, the whalers too were apt to consider ice merely as a nuisance which hindered them in their pursuit of whales, but, when pelagic whaling began in earnest in the Antarctic in the early I930's, the Norwegians, especially the association of companies concerned with the insurance of the ships, became interested and, following a short paper by Hansen (1934), an atlas edited by Hansen (1936) was produced to show the probable limits of the ice edge in the whaling areas during certain summer months.

This lack of knowledge - not only of pack ice but chiefly of the surface currents and meteorological conditions generally - nearly caused the loss of Discovery II early in I932. As it was, she was caught in a tongue of heavy pack ice when northward bound from the then open 
waters of the Weddell Sea to South Georgia, a shift of wind occurred and, as the wind was then blowing hard from a direction diametrically opposite to that in which the surface current was flowing, the ship was subjected to considerable ice pressure. She was lucky to escape with no worse damage than the loss of all the fuel oil from a wing tank, a serious leak in the forehold, and a twisted rudder stock; damage which was easily repairable in Cape Town. It was many years later before we fully understood the movement of the surface water and pack ice in this area, and realized that this tongue of ice exists to a greater or lesser extent during the whole year. In it will be found much "rafted" ice, i.e. large slabs of pack ice which have been forced up on top of others in conditions such as Discovery II found in I932. It was under similar circumstances that the Endurance was lost in I 916 after being imprisoned for the winter months. In recent years, doubts have sometimes been expressed about the assumption that there is little change from year to year in the northern limit of the pack ice from season to season. It is therefore of considerable interest to note (Herdman, I959) that, in December

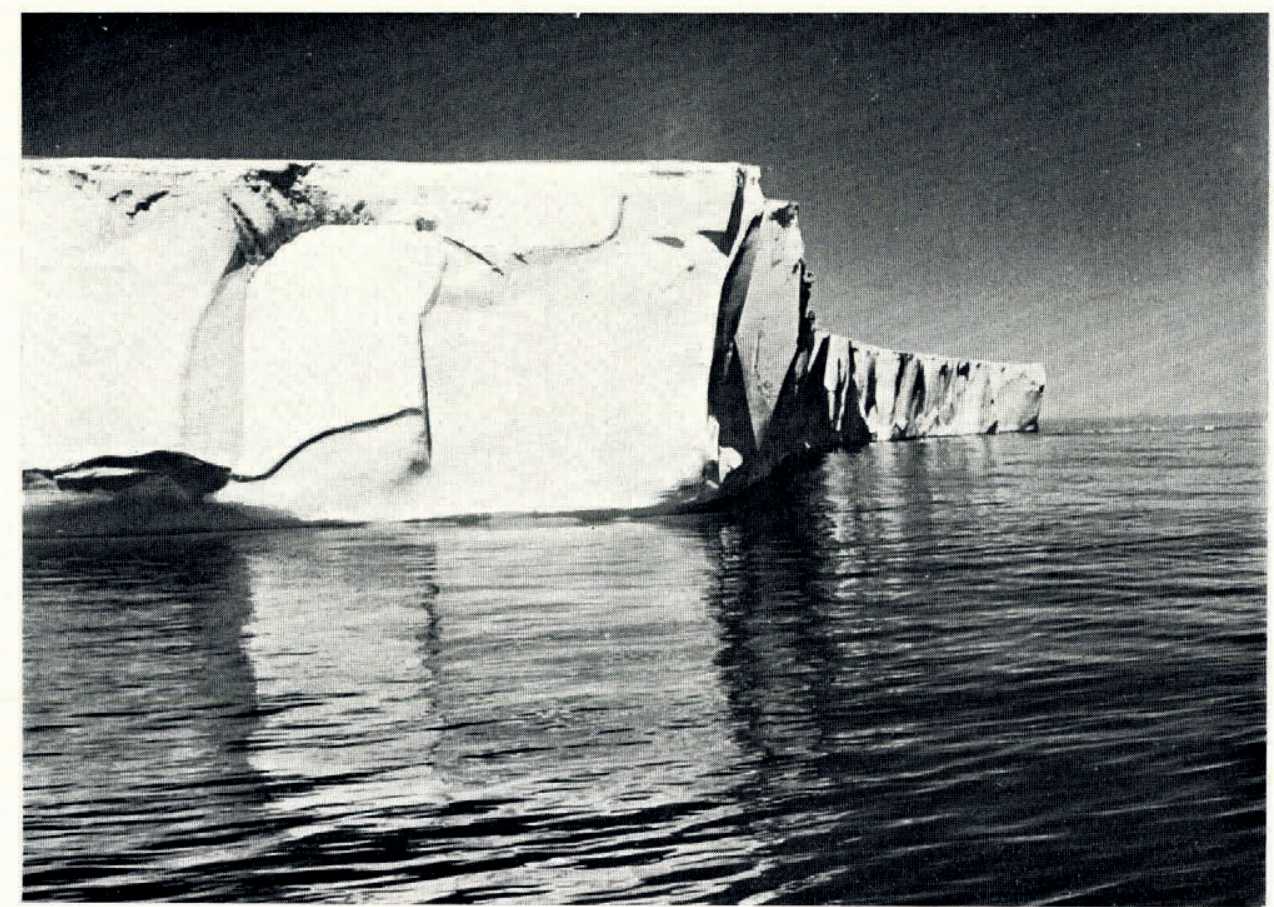

Fig. 5. Very large new tabular iceberg, $75 \mathrm{ft}$. (23 m.) high, between the South Orkney and South Sandwich Islands. Photograph by National Institute of Oceanography

I772, Captain James Cook found this tongue of pack ice lying approximately within the limits now shown by Mackintosh and Herdman (1940). Sailing south from the Cape to look for a southern continent, Cook found himself being forced steadily to the south-east and then east, and when he turned south again in long. $3 \mathrm{I}^{\circ} 33^{\prime} \mathrm{E}$. the ships sailed into clear water before being finally stopped by impenetrable pack ice. They were now west and some four degrees south of the position where they had turned south and, on continuing to the west, fields of pack ice were met to the north of their track. Now that we have a better knowledgelaboriously built up over many years - of the oceanic circulation for this area, much is explained. Not only is the distribution and movement of the pack ice more clearly understood, but we can now safely assume that the majority of the very large number of icebergs reported 
every year in the Atlantic sector of the Southern Ocean derive from the ice shelf at the head of the Weddell Sea.

The build-up of data on the Antarctic pack ice was hampered greatly by the lack of observing ships. In summer the whalers were very helpful but it was another story in winter. Few ships visit these waters at any time, and certainly not from choice in the winter months. Consequently, most of our knowledge of winter conditions stems from the winter cruises by Discovery $I I$ in 1932 , $193^{8}$ and $195^{1}$. In $193^{2}$ and in $195 \mathrm{I}$ the ship circumnavigated the continent, carrying out her normal scientific programme in generally foul weather and long hours of darkness, and with little or no chance of obtaining shelter from the persistent gales. With only one observing ship the observations are, naturally, widely separated in time and distance and are probably barely sufficient to provide a general picture. Nevertheless, there are enough observations to lead us to believe that the limits tentatively suggested by Mackintosh and Herdman (I940) are tolerably accurate. That there may be considerable variations in these limits at times was established during a series of cruises between South Africa and the edge of the pack ice in the late winter months of i 938 . For instance, in July

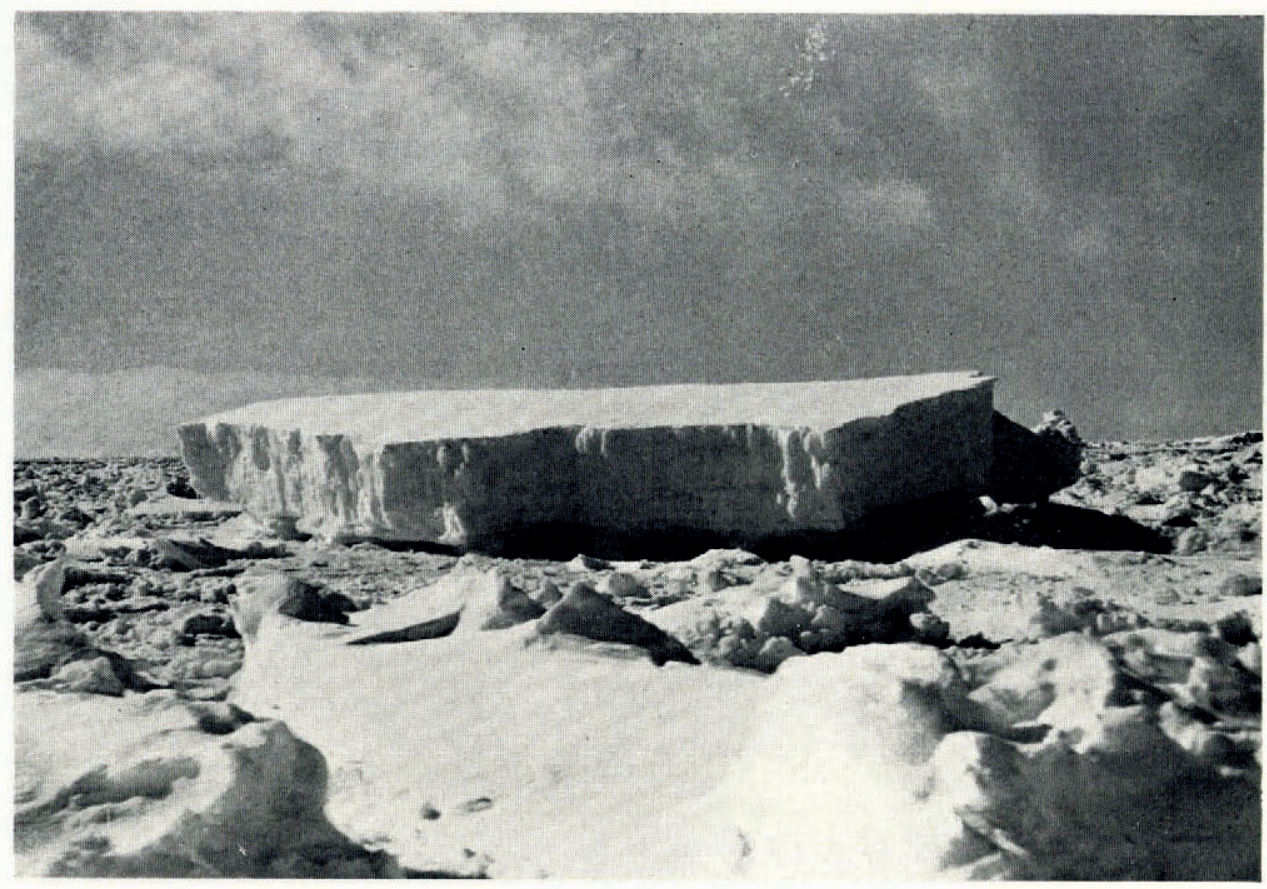

Fig. 6. Heavy rafled pack ice near Hugo Island. December 1930. Photograph by . National Institute of Oceanography

and September the northern edge of the pack ice, in the longitude of Greenwich lay in lat. $55^{\circ} 32^{\prime} \mathrm{S}$. and $55^{\circ} 35^{\prime} \mathrm{S}$. respectively; whereas in August the main body of ice lay in lat. $57^{\circ}$ I $8^{\prime} \mathrm{S}$. Here, conditions in the sea were ideal for the formation of ice, the sea being calm, with a surface temperature of $-\mathrm{I} \cdot 6^{\circ} \mathrm{C}$. and the air temperature at $-2 \cdot 0^{\circ} \mathrm{C}$. On the other hand, in these notoriously stormy regions, there may have been a succession of southerly gales which would have dispersed the newly formed ice, and driven it north to melt under the influence of the warmer north-westerly winds and the less cold water. It has been suggested that the ice edge reported in July and September might only have been an outlying belt of ice, and that probably there was clear water between this and the main body of pack ice. All 
indications were that an extensive ice field lay to the south on each occasion - since there was unbroken "blink" with no signs of a "water" sky. And, with a surface temperature of $-1.6^{\circ} \mathrm{C}$., which verges on the "critical" temperature for the freezing of salt water for the salinity in situ, it is most unlikely that, given calm conditions, the sea would have remained unfrozen for very long.

The ship's and meteorological logbooks of Discovery II contain many observations and records of Antarctic icebergs but, with the exception of a short paper by Kemp and Wordie (r933) on "black" and morainic bergs, little has appeared so far in the literature. Briefly, Discovery II's observations lead us to believe that the majority of icebergs found in the Southern Ocean derive from the extensive ice shelves in the Ross and Weddell Seas. The odd morainic iceberg sighted near the continent in summer probably derives from glacier ice but the tabular iceberg quite definitely has its origin in shelf ice. In the course of her voyages in the Southern Ocean and in Antarctic waters the ship must have sighted many thousands of icebergs; it is hoped some day to collate all this material for publication.

MS. received $3^{I}$ December 1962

\section{REFERENCES}

Hansen, H. E. 1934. Limits of the pack-ice in the Antarctic in the area between $40^{\circ} \mathrm{W}$. and $110^{\circ}$ E. Hvalradets Skrifter, Nr. 9, p. 39-4I, pl. iv-vii.

Hansen, H. E., ed. 1936. Atlas over Antarktis og Sydishavet. Sandefjord, Hvalfangernes Assuranceforening.

Herdman, H. F. P. 1959. Early discoverers, XII. Some notes on sea ice observed by Captain James Cook, R.N., during his circumnavigation of Antarctica, I 772-75. Journal of Glaciology, Vol. 3, No. 26, p. 534-41.

Kemp, S. W., and Wordie, J. M. I933. Observations on certain Antarctic icebergs. Geographical fournal, Vol. 8I, No. 5 , p. $428-34$.

Mackintosh, N. A., and Herdman, H. F. P. 1940. Distribution of the pack-ice in the Southern Ocean. Disccvery Reports, Vol. 19, p. 285-96, pl. lxiv-xcv. 